Neurodegenerative Dis 2011;8:262-274

DOI: $10.1159 / 000321547$
Received: July 8, 2010

Accepted after revision: September 8, 2010

Published online: December 3, 2010

\title{
TDP-43-Based Animal Models of Neurodegeneration: New Insights into ALS Pathology and Pathophysiology
}

\author{
Iga Wegorzewska ${ }^{\mathrm{a}}$ Robert H. Baloh ${ }^{\mathrm{a}, \mathrm{b}}$ \\ ${ }^{a}$ Neuromuscular Division, Department of Neurology, and ${ }^{b}$ Hope Center for Neurological Disorders, \\ Washington University, Saint Louis, Mo., USA
}

\section{Key Words}

Amyotrophic lateral sclerosis - Frontotemporal lobar

degeneration $\cdot$ Motor neuron disease $\cdot$ Protein

aggregation $\cdot$ TDP-43

\begin{abstract}
The clinical and pathological overlap between amyotrophic lateral sclerosis (ALS) and frontotemporal lobar degeneration (FTLD) suggests these diseases share common underlying mechanisms, a suggestion underscored by the discovery that TDP-43 inclusions are a key pathologic feature in both ALS and FTLD. This finding, combined with the identification of TDP-43 mutations in ALS, directly implicates this DNA/ RNA binding protein in disease pathogenesis in ALS and FTLD. However, many key questions remain, including what is the normal function of TDP-43, and whether disease-associated mutations produce toxicity in the nucleus, cytoplasm or both. Furthermore, although pathologic TDP-43 inclusions are clearly associated with many forms of neurodegeneration, whether TDP-43 aggregation is a key step in the pathogenesis in ALS, FTLD and other disorders remains to be proven. This review will compare the features of numerous recently developed animal models of TDP-43-related neurodegeneration, and discuss how they contribute to our understanding of the pathogenesis of human ALS and FTLD.
\end{abstract}

Copyright ๑ 2010 S. Karger AG, Basel

\section{Introduction}

Amyotrophic lateral sclerosis (ALS) is a progressive, fatal disorder characterized by muscle weakness and spasticity due to the degeneration of motor neurons in the brain and spinal cord. It is the most common adult motor neuron disease with a 3- to 5-year disease course, ultimately ending in respiratory failure [1]. Most cases of ALS are sporadic, with about $10 \%$ having a family history of the disease [2]. Of the familial cases, dominantly inherited mutations in the $\mathrm{Cu} / \mathrm{Zn}$ superoxide dismutase SOD1 are the most commonly identified cause, seen in $\sim 20 \%$ [3]. This discovery became the basis for the widely used transgenic SOD1 rodent models that have been a major focus of basic research and preclinical testing for ALS. While SOD1 mice recapitulate key features of human ALS and have led to the identification of numerous molecular pathways involved in disease, the mechanism of SOD1 mediated motor neuron toxicity remains incompletely understood [1], and pharmacologic agents that modify disease course in SOD1-based rodent models have not produced successful therapies for patients [4]. This suggests that SOD1 models may not accurately reflect the common sporadic form of ALS, and supports that additional animal models would be useful to advance understanding of disease mechanisms and improve therapeutics development.

\section{KARGER}

Fax +4161306 1234

E-Mail karger@karger.ch

www.karger.com
(C) 2010 S. Karger AG, Basel

Accessible online at: www.karger.com/ndd
Robert H. Baloh, MD, $\mathrm{PhD}$

Department of Neurology, 660 South Euclid Avenue

Box 8111, Saint Louis, MO 63110 (USA)

Tel. +1 314362 3752, Fax +1 314362 6981, E-Mail rbaloh@wustl.edu 


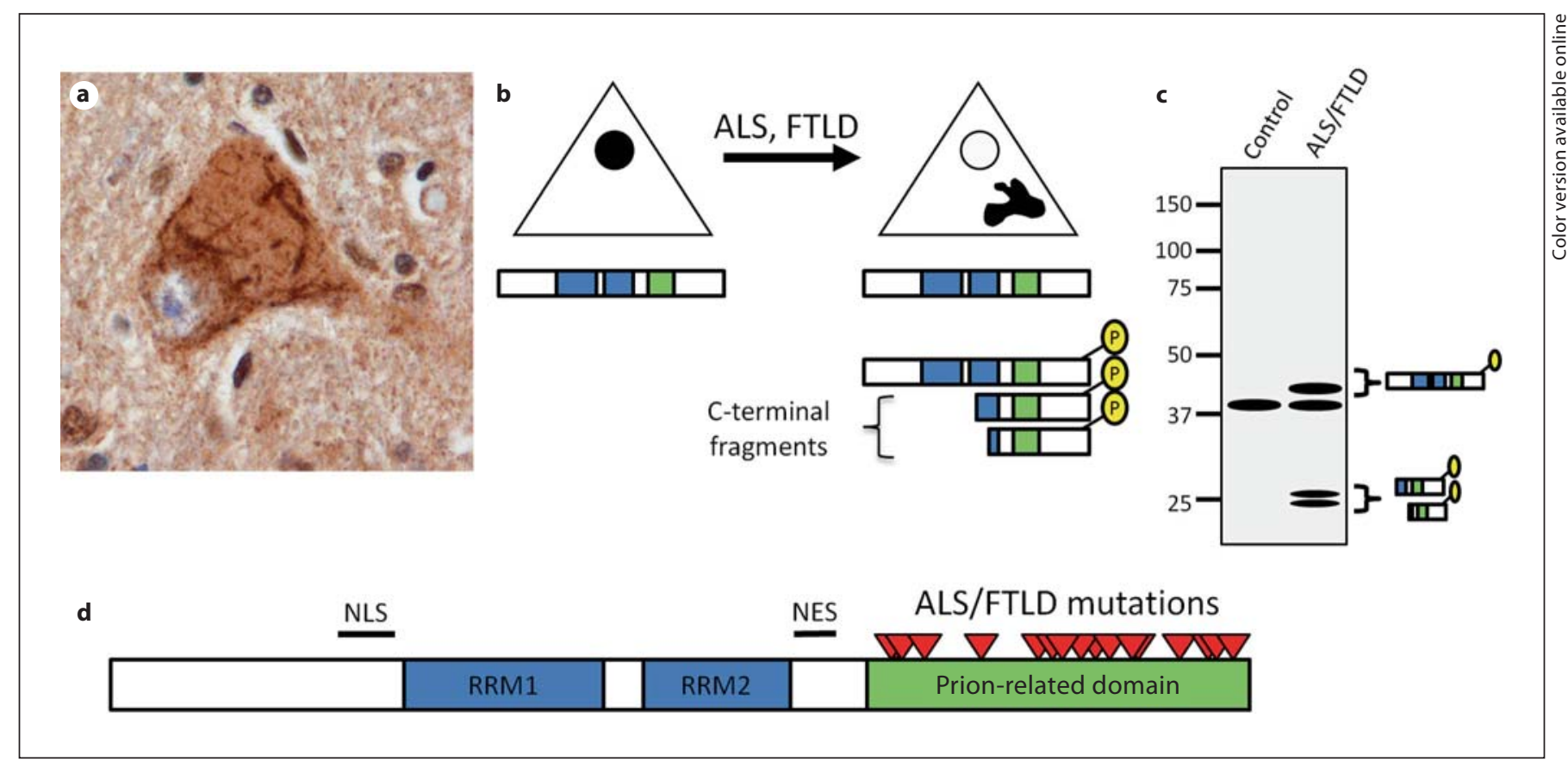

Fig. 1. Pathology and genetics of TDP-43 in ALS and FTLD. a Skein-like TDP-43 inclusions in the cytoplasm of a spinal motor neuron in a case of ALS, with loss of normal nuclear staining. Photomicrograph courtesy of Dr. Nigel Cairns. b Schematic diagram of TDP-43 pathology in affected neurons in ALS and FTLD. Normally, TDP-43 is present as full-length protein in the nucleus. In cases of ALS and FTLD, inclusions of the protein appear pre-

Although ALS is traditionally thought of as a disease which spares cognitive function, recent studies support that frontotemporal lobar degeneration (FTLD) is common in ALS patients [5]. FTLD is a dementing disorder due to degeneration of non-motor frontal and temporal lobe structures, typically characterized by behavioral changes and language dysfunction [6,7]. Likewise, examination of a cohort of FTLD patients found that up to $36 \%$ have evidence of clinical or subclinical motor neuron disease, suggesting that FTLD and ALS may actually represent different ends of a single clinical spectrum [8]. The idea that ALS and FTLD represent different clinical manifestations of a single underlying neurodegenerative disease first gained broader support after inclusions of insoluble TDP-43 [43 kDa transactivation response (TAR) DNA-binding protein] were reported in both ALS and FTLD [9]. While normally located in the nucleus, in ALS and FTLD tissues TDP-43 was found to be accumulated in cytoplasmic inclusions, frequently with diminished nuclear staining, as well as post-translationally modified (phosphorylated, ubiquitinated, and cleaved into C-ter- dominantly in the cytosol, with loss of nuclear staining. This correlates with the presence of cleaved and phosphorylated C-terminal fragments observed on Western blotting (c). d Line diagram of TDP-43 showing the RNA binding motifs (RRM1 and RRM2), nuclear localization signal (NLS), nuclear export signal (NES), and location of the ALS/FTLD associated mutations (arrowheads) in the C-terminal prion-related domain. minal fragments; fig. 1) [9]. TDP-43 is a multi-functional DNA/RNA binding protein [10-12] known to play a role in transcriptional and splicing regulation, micro-RNA processing, and RNA transport [reviewed in 13].

The subsequent identification of missense mutations in TDP-43 in familial and sporadic ALS [14-18] and FTLD patients [19-22] confirmed that TDP-43 can be directly involved in the pathogenesis of ALS/FTLD, at least in these rare familial cases. Essentially all of the dominantly inherited missense mutations in TDP-43 are located in the C-terminal prion-related domain [23], but how these mutations alter the normal functions of the protein remain poorly understood (fig. 1). The recent identification of mutations in another RNA binding protein (FUS/TLS) in familial ALS further argues for the importance of RNA processing in ALS pathogenesis [24,25]. Studies suggest TDP-43 and FUS/TLS are located in the same nuclear complexes [26, 27], and inclusions in sporadic ALS stain for both proteins [28], supporting that TDP-43 and FUS/TLS may function in similar molecular pathways. 
While mutations in TDP-43 are only observed in ALS and FTLD, TDP-43 inclusions are present in at least a subset of cases of most neurodegenerative diseases. These include Alzheimer's disease, Huntington's disease, and even inclusion body myopathies [29-32]. It remains to be determined in diseases other than ALS and FTLD whether TDP-43 is central to the pathophysiology, or rather is a nonspecific marker of neurodegeneration and cellular stress.

Transgenic animal models play a central role in neurodegenerative disease research, as they provide a useful avenue for investigating disease pathomechanisms. Here we review recently developed vertebrate and invertebrate models of TDP-43-related neurodegeneration, and discuss how these influence our understanding of human ALS and FTLD.

\section{Overview of TDP-43 Transgenic Rodent Models}

As TDP-43 mutations in ALS are dominantly inherited, the first approaches taken to modeling TDP-43-related neurodegeneration in rodents were to express human TDP-43 cDNAs (either wild-type or disease mutants) under the control of various exogenous promoters (table 1). This has proved challenging depending on the promoter used, because high level expression of wildtype TDP-43 can be toxic in cultured cells [33-35]. This is in marked contrast to wild-type SOD1, which is nontoxic when expressed even at very high levels. While the first transgenic mouse model of SOD1 [36] was published within a year of reports of ALS-associated mutations in SOD1 [3], it took several years for the first mouse models to be developed after TDP-43 was found to be a major disease protein in ALS [37-42]. Three groups reported that when either wild-type or ALS-mutant TDP-43 was driven by the mouse prion protein promoter expressed widely during development, few founders were obtained with most dying shortly after birth, suggesting marked developmental toxicity of TDP-43 overexpression [37, 39, 43]. Alternative approaches using transgenic expression of TDP-43 under either the Thy-1.2 or CaMKII promoters (mainly expressed postnatally) in mice, or an inducible tetracycline (Tet) regulatory system in rats, were able to circumvent developmental toxicity [38, 40, 42, 43]. The following is a brief summary of the experimental approach and phenotype of each of the different rodent models, grouped by the promoters used to drive TDP- 43 expression.

\section{Mouse Prion Protein Promoter-Based TDP-43}

\section{Overexpression}

The mouse prion protein (mPrp) promoter drives expression of transgenes at high levels in the nervous system, and has successfully been used to model dominantly inherited forms of neurodegenerative diseases [44, 45]. Using the mPrp promoter, our group reported a transgenic mouse line that expressed a human TDP-43 cDNA transgene with the A315T mutation, carrying an aminoterminal Flag tag (Prp-TDP43 $\left.{ }^{\mathrm{A} 315 \mathrm{~T}}\right)$. This drove expression in most tissues, but was highest in neurons and glia in the brain and spinal cord, $\sim 3$-fold over endogenous TDP-43 [37]. Prp-TDP43 ${ }^{\mathrm{A} 315 \mathrm{~T}}$ mice were born at expected mendelian ratios, appeared normal and weighed the same as their littermates until early adulthood. At about 3 months of age, Prp-TDP43 ${ }^{\text {A315T }}$ mice developed an abnormal gait, and at $\sim 4.5$ months started losing weight, with progression of their gait abnormality and death by $\sim 5$ months from inability to right or feed themselves. Although we were unable to propagate a matching wildtype TDP-43 line, we observed numerous founders of both WT and A315T mutant which died prior to weaning similar to other reports [unpubl. data].

Two other groups have also reported transgenic mice expressing either wild-type or disease mutant TDP-43 using the mPrp promoter $[39,41]$. Overall the phenotype of these mice was quite similar to the Prp-TDP43 ${ }^{\mathrm{A} 315 \mathrm{~T}}$ line. Stallings et al. [39] reported that numerous founders expressing high levels of WT, A315T or M337V TDP-43 showed runting and early demise before the lines could be propagated. A line expressing 'intermediate' levels ( $\sim 4$-fold above endogenous) of TDP43 $3^{\mathrm{A} 315 \mathrm{~T}}$ developed a progressive motor phenotype and survived $\sim 75$ days, with findings of muscle denervation, ubiquitin-positive inclusions in motor neurons, and gliosis in the ventral horn on histology. By comparison, TDP43 ${ }^{\mathrm{WT}}$ expression (at slightly lower levels) under the mPrp promoter did not produce an overt phenotype out to 11 months, though rare neurons in the CNS showed a diffuse increase in cytoplasmic ubiquitin staining.

$\mathrm{Xu}$ et al. [41] reported analysis of a line expressing TDP43 ${ }^{\mathrm{WT}}$ under the mPrp promoter. As their hemizygous mice did not have a behavioral or pathologic phenotype, they focused analysis on homozygous transgenic mice. Homozygous Prp-TDP43 ${ }^{\mathrm{WT}}$ mice developed a severe early onset phenotype, characterized by weight loss starting at 14 days, progressive gait disorder, and death by 1-2 months. The fact that hemizygous mice were normal, but homozygous mice developed severe early lethality, supports that not only is there a dose dependency to TDP- 
Table 1. Summary of TDP-43 transgenic rodent models

\begin{tabular}{|c|c|c|c|c|c|c|c|}
\hline Promoter & Transgene & Species & $\begin{array}{l}\text { Expression } \\
\text { (fold over } \\
\text { endogenous) }\end{array}$ & $\begin{array}{l}\text { Symptom } \\
\text { onset, days }\end{array}$ & $\begin{array}{l}\text { Survival } \\
\text { days }\end{array}$ & Pathology & Reference \\
\hline \multirow{2}{*}{$\mathrm{mPrp}$} & Human TDP-43 cDNA & Mouse & $\begin{array}{l}\text { Hemi: } 1.9 \\
\text { Homo: } 2.5\end{array}$ & $\begin{array}{l}\text { None } \\
14\end{array}$ & $\begin{array}{l}\text { Normal } \\
30-60\end{array}$ & $\begin{array}{l}\text { Axonal degeneration without cell loss } \\
\text { Astrocytic and microglial activation } \\
\text { Rare phospho-TDP43 inclusions } \\
\text { C-terminal TDP-43 fragments } \\
\text { Mitochondrial accumulations }\end{array}$ & $\begin{array}{l}\text { Xu et al., } \\
2010[41]\end{array}$ \\
\hline & $\begin{array}{l}\text { Human TDP-43 cDNA } \\
\text { A315T mutation } \\
\text { N-terminal Flag }\end{array}$ & Mouse & 3 & 90 & 153 & $\begin{array}{l}\text { Upper and lower motor neuron/axon } \\
\text { degeneration } \\
\sim 20 \% \text { loss of LMN at end stage } \\
\text { Astrocytic and microglial activation } \\
\text { Rare phospho-TDP43 inclusions }{ }^{c} \\
\text { Loss of nuclear TDP-43 staining } \\
\text { C-terminal TDP-43 fragments }\end{array}$ & $\begin{array}{l}\text { Wegorzewska } \\
\text { et al., } 2009 \\
{[37]}\end{array}$ \\
\hline \multirow[t]{2}{*}{ Thyl.2 } & Human TDP-43 cDNA & Mouse & $\begin{array}{l}\text { Hemi: } 1.9-2.8^{\mathrm{a}} \\
\text { Homo: } 3.8-5.1^{\mathrm{a}}\end{array}$ & $\begin{array}{l}\text { None } \\
14-60^{\mathrm{a}}\end{array}$ & $\begin{array}{l}\text { Normal } \\
30-200^{\text {a }}\end{array}$ & $\begin{array}{l}\text { Upper and lower motor neuron degeneration } \\
\sim 30 \% \text { loss of motor cortical layer V neurons } \\
\sim 25 \% \text { loss of LMN at end stage } \\
\text { Astrocytic and microglial activation } \\
\text { Rare TDP-43 and phospho-TDP-43 inclusions } \\
\text { Loss of nuclear TDP-43 staining } \\
\text { C-terminal TDP-43 fragments }\end{array}$ & $\begin{array}{l}\text { Wils et al., } \\
2010[38]\end{array}$ \\
\hline & $\begin{array}{l}\text { Human TDP- } 43 \text { cDNA } \\
\text { (line W3) }\end{array}$ & Mouse & $\begin{array}{l}\text { Males: } 3.6 \\
\text { Females: } 1.3\end{array}$ & $\begin{array}{l}14-18 \\
90\end{array}$ & Normal & $\begin{array}{l}\text { Abnormal NMJ staining, axonal atrophy } \\
\text { without loss } \\
\text { No TDP-43 or phospho-TDP- } 43 \text { inclusions } \\
\text { Mitochondrial accumulations } \\
\text { Increased number of Gemini bodies }\end{array}$ & $\begin{array}{l}\text { Shan et al., } \\
2010[42]\end{array}$ \\
\hline TRE & $\begin{array}{l}\text { Human TDP- } 43 \text { cDNA } \\
\text { M337V mutation }\end{array}$ & Rat & NR & $\begin{array}{l}\text { Males: } 32^{\mathrm{b}} \\
\text { Females: } 34^{\mathrm{b}}\end{array}$ & $\begin{array}{l}46^{\mathrm{b}} \\
49^{\mathrm{b}}\end{array}$ & $\begin{array}{l}\text { Lower motor neuron/axon degeneration } \\
\sim 17 \% \text { loss of LMN at end stage } \\
\text { Astrocytic and microglial activation } \\
\text { Rare phospho-TDP- } 43 \text { inclusions (cortex only) }\end{array}$ & $\begin{array}{l}\text { Zhou et al., } \\
2010[43]\end{array}$ \\
\hline \multicolumn{5}{|c|}{$\begin{array}{l}\text { Although several groups reported founder analysis (see text), only lines } \\
\text { which could be propagated are listed. Symptom onset was variously de- } \\
\text { fined as the beginning of abnormal gait, weight loss or tremor. mPrp = } \\
\text { Mouse prion protein promoter; CaMKII = calcium/calmodulin-dependent } \\
\text { kinase II; TRE = tetracycline response element; LMN = lower motor neu- } \\
\text { rons; NR = not reported. }\end{array}$} & \multicolumn{3}{|c|}{$\begin{array}{l}\text { a Range of expression, onset and survival varied across several lines. } \\
\text { b Transgene induction } 4 \text { days before birth, line } 7 . \\
{ }^{c} \text { Wegorzewska and Baloh [unpubl. data]. }\end{array}$} \\
\hline
\end{tabular}


43 overexpression toxicity in vivo, but there is also a strong threshold effect (fig. 2).

\section{Thy-1.2 Promoter-Based TDP-43 Overexpression}

The Thy-1.2 promoter was engineered to drive neuronal expression of transgenes, such that insertion of the transgene removes the transcriptional control elements for thymic expression, leaving only neuronal expression intact $[46,47]$. An additional well described property of Thy-1.2 is the variegate expression patterns that it produces, with marked line to line variability based on insertion site effects [48]. Wils et al. [38] reported that expression of wild-type human TDP-43 under the Thy-1.2 promoter produced a similar phenotype to the mPrp promoter-based lines, with rapidly progressive paralysis and neurodegeneration in the highest expressing line. Similar to the mPrp lines, the Thy1.2-TDP43 $3^{\mathrm{WT}}$ lines demonstrated both dose-dependency and a threshold effect of TDP-43 toxicity. The highest expressing lines crossed to homozygosity developed gait abnormalities at 2 weeks of life and survived less than 1 month, with lower-expressing homozygous lines surviving to 6.7 months, and hemizygous lines with little or no phenotype and a normal lifespan. They estimated that the highest expressing line was $\sim 5$-fold over endogenous TDP-43 levels in neurons cultured from the mice; however, given the marked variability in Thy-1.2 promoter expression in different neuronal subtypes [48], TDP-43 expression may be much higher or lower in different neuronal populations in the mature animals.

A second group also recently reported several transgenic mouse lines expressing wild-type TDP-43 under the Thy-1.2 promoter, and observed similar results [42]. The highest expressing line was runted and died by 3 weeks of age, while lower expressing lines developed body weight reduction and gait abnormalities without premature death. The lower level expressing lines showed sexual dimorphism, with lower transgene expression level and a milder phenotype observed in female mice (see table 1). Histologic analysis of a lower expressing line showed that though there was no motor neuron loss, neuromuscular junctions and axonal mitochondria were morphologically abnormal, and the origin of the tremor and gait disorder was thought to be functional rather than degenerative [42].

\section{CaMKII Promoter-Based TDP-43 Overexpression}

The $\mathrm{Ca}^{2+} /$ calmodulin-dependent kinase II (CaMKII) promoter drives neuronal expression predominantly in the forebrain (neocortex, hippocampus, amygdala and

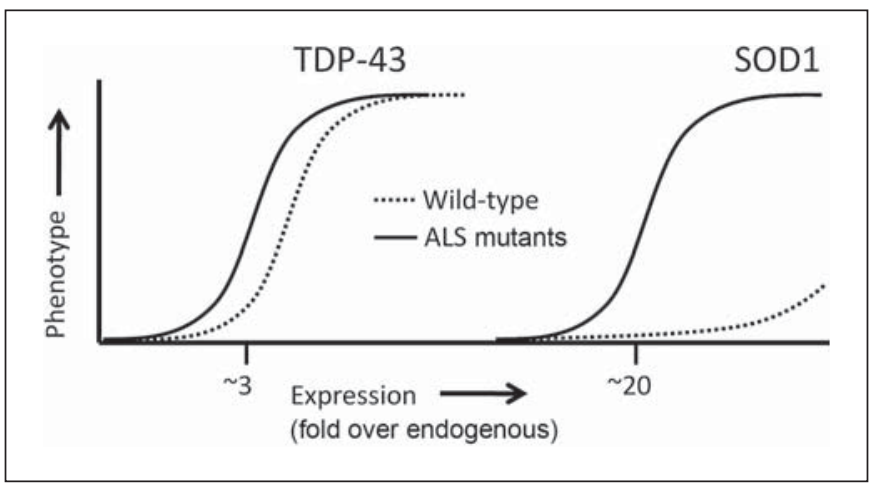

Fig. 2. Schematic plot of the relationship between expression levels of TDP-43 and SOD1 and the development of features of ALS ('phenotype'). Low levels of TDP-43 produce little or no detectable phenotype. At a threshold of expression around 3-fold above endogenous levels, mice begin to develop features of ALS and FTLD pathology. Although the ALS-associated mutants appear to be more toxic than the wild-type protein, this still needs to be carefully examined given the mix of different promoters used to make existing mouse lines. In the case of SOD1, much higher levels are required to produce toxicity $(\sim 20$ fold); however, the difference in toxicity between mutant and wild-type SOD1 forms is much more pronounced.

basal ganglia), and hence is similar to the Thy-1.2 promoter except it does not drive expression in the brainstem or spinal cord [49]. A transgenic line expressing wildtype mouse TDP-43 under the CaMKII promoter developed behavioral and motor abnormalities as measured on Morris water maze and rotarod testing, with a slightly shortened lifespan (495 days for CaMKII-TDP43 ${ }^{\mathrm{WT}}$ vs. 632 days for nontransgenic mice) [40]. Brain atrophy and cortical neuron loss were observed in 6-month-old mice, and attenuated LTP was present in hippocampal slice preps. Given that the CaMKII promoter is expressed in upper motor neurons in the cortex, degeneration of the descending corticospinal tracts was likely responsible for the abnormal clasping reflex and motor testing observed in these mice [40], indicating they likely have features of both FTLD and primary lateral sclerosis, an upper motor neuron predominant variant of ALS. Of note, this is the only transgenic reported thus far using the mouse cDNA, demonstrating that toxicity from TDP-43 overexpression is not specific to the human protein.

\section{Endogenous and Tet-Inducible Promoter-Based \\ Rat Models}

Wild-type and mutant TDP-43-expressing rat models have also been reported [43]. Using a human TDP-43 ' $\mathrm{mi}$ - 
nigene' construct with all exons and flanking control regions presumably containing the endogenous promoter, rats expressing wild-type or M337V mutant TDP-43 minigenes at similar levels were generated. While wild-type TDP-43-expressing rats were normal, founders expressing the M337V mutant showed a severe progressive paralysis phenotype and did not survive long enough to breed. This suggested that disease mutant TDP- 43 driven at the same level and under the same promoter is more toxic than the wild-type protein. This group also made rats expressing a TDP $43^{\mathrm{M} 337 \mathrm{~V}}$ mutant cDNA under a Tetracycline repressible promoter, and found that induction of transgene expression shortly before birth produced a dose-dependent progressive gait disorder with degeneration of spinal motor neurons, similar to the mouse models described above [43].

Taken together these studies indicate several important points: (1) transgenic expression of TDP-43 in neurons produces neurodegeneration in a dose-dependent fashion in rodents; (2) there appears to be a threshold effect, i.e. TDP-43 expression below a certain level yields little detectable toxicity, while expression above that level leads to neurodegeneration; (3) wild-type TDP-43 can cause similar toxicity to ALS-associated disease mutants if driven at high enough levels, and (4) ALS-associated disease mutants appear to be more toxic than wild-type TDP-43, though direct comparisons are still lacking (fig. 2).

\section{Insights from Animal Models on the Mechanism of TDP-43-Related Neurodegeneration}

If these transgenic models produce a neurodegenerative phenotype with features of ALS and FTLD, what insight do they provide into the mechanism of TDP-43related neurodegeneration seen in familial ALS from TDP-43 mutations, and possibly other disorders where abnormal TDP-43 pathology (i.e. cytoplasmic inclusions, nuclear clearing) is present? Based on observations from human pathologic material and studies in cultured cells, several hypotheses regarding the mechanism of TDP-43related neurodegeneration have been proposed $[13,50$, 51]. These can be broadly broken down into 2 themes nuclear toxicity and cytoplasmic toxicity. The nuclear toxicity theory postulates that either alteration or loss of TDP-43 nuclear function (transcription, splicing, miRNA processing, etc.) leads to toxicity. The cytoplasmic toxicity theory states that TDP-43 mislocalized to the cytoplasm (either soluble or insoluble, full length or cleaved into C-terminal fragments) is the primary toxic event. This cytoplasmic toxicity may occur either by sequestering and inactivating endogenous nuclear TDP-43 (hence unifying the nuclear and cytoplasmic theories) or through some other unrelated toxic gain of function (promotion of stress granule formation, etc.). In the following sections we will discuss insights into these proposed mechanisms that can be gleaned from existing rodent models.

\section{Cytoplasmic TDP-43 Inclusions as Mediators of}

TDP-43-Related Toxicity

Cytoplasmic TDP-43 inclusions are present in most cases of ALS and FTLD-U (FTLD with ubiquitinated inclusions) $[9,52,53]$. Abnormal protein inclusions are a hallmark finding in most neurodegenerative diseases, and debate continues in each of these diseases as to whether inclusions are toxic to neurons, are protective, or are simply a by-product of another toxic process involving the protein in question. In the case of TDP-43, cytoplasmic inclusions form the basis of 1 version of the cytoplasmic toxicity theory - that inclusions of TDP-43 themselves mediate neurodegeneration.

One striking feature of most of the reported rodent models is that while ubiquitinated inclusions are common in vulnerable neurons prior to degeneration, these inclusions either rarely $[38,39,41]$ or never $[37,42]$ stain for TDP-43 itself. Antibodies which stain phosphorylated TDP-43 appear to be more sensitive at detecting these rare TDP-43 positive inclusions. Although the frequent ubiquitinated inclusions in Prp-TDP43 ${ }^{\mathrm{A} 315 \mathrm{~T}}$ mice do not stain for TDP-43, subsequent examination using phospho-specific TDP-43 antibodies has confirmed that a minority of inclusions do stain for phosphorylated TDP-43 [unpubl. data]. However, the fact remains that the majority of ubiquitinated inclusions in the reported TDP-43 transgenic rodent models do not stain for TDP-43 or phospho-TDP-43. Though it is possible that this is due to technical differences, after 5 independent reports of similar findings this becomes less likely.

If the frequent ubiquitinated inclusions in TDP-43based transgenic models rarely contain TDP-43, what do they contain? Two recent reports used electron microscopy and immunostaining to show that spinal motor neurons of TDP-43 transgenic animals contained large perinuclear accumulations of mitochondria [41, 42]. These mitochondrial accumulations were observed whether wild-type TDP-43 was driven with Thy-1.2 or mPrp, and we have also observed similar mitochondrial accumulations in the Prp-TDP43 ${ }^{\mathrm{A} 315 \mathrm{~T}}$ line [Wegorzewska and Baloh, unpubl. data], indicating this is not specific to 
a particular promoter or expression of wild-type versus ALS disease mutant constructs. Further work will be needed to determine the significance of this finding, but given several lines of evidence implicating mitochondrial dysfunction in SOD1 models of ALS [54], this presents a possible common downstream pathway in both TDP-43and SOD1-related ALS.

While the fact that TDP-43 inclusions are rare despite widespread neurodegeneration is clearly contrary to the hypothesis that cytoplasmic inclusions of TDP-43 are a necessary step for TDP-43-related neurodegeneration, it does not refute the idea that aberrant TDP-43 aggregation may still play a key role in toxicity. TDP-43 is an inherently aggregation-prone protein [55], particularly in its $\mathrm{C}$-terminal region which contains a $\mathrm{Q} / \mathrm{N}$ rich prionrelated domain [23]. Indeed, soluble oligomeric species of neurodegenerative disease-related proteins are being recognized as potential key players in disease pathogenesis, and there is evidence that such species (possibly in the form of C-terminal fragments) are present in TDP-43 transgenic rodent models.

\section{C-Terminal Fragments as Potential Mediators of}

TDP-43 Toxicity

A second version of the cytoplasmic toxicity theory posits that cleaved C-terminal fragments of TDP-43 mediate TDP-43-related neurodegeneration. TDP-43 was initially found to be proteolytically cleaved into C-terminal fragments in tissue from ALS and FTLD-U patients, but not in tissues from patients with other neurodegenerative diseases [9]. These C-terminal fragments were seen in the detergent-insoluble phase of biochemically fractionated brain tissue, and have been suggested to form the basis of TDP-43 cytoplasmic inclusions [9]. In vitro evidence also supports the idea that C-terminal fragments of TDP-43 may mediate toxicity, as the expression of engineered C-terminal TDP-43 fragments is more toxic to cultured cells than full length TDP-43 $[34,56]$. Of note, 35 - and $25-\mathrm{kDa}$ C-terminal fragments of TDP-43 are observed in all but 1 of the rodent models generated, expressing either the mutant or wild-type forms of TDP-43, under various promoters $[37-41,43]$. In the Prp-TDP43 ${ }^{\mathrm{A} 315 \mathrm{~T}}$ mice these were present before behavioral or histologic abnormalities occurred, supporting a possible early or causative role [37]. Surprisingly, in the rodent models Cterminal fragments were present predominantly in the detergent-soluble fractions, unlike that observed in human patients, perhaps correlating to the fact that cytoplasmic TDP-43 inclusions are rarely present. In summary, existing rodent models support the possibility that C- terminal TDP-43 fragments could play a direct toxic role in TDP-43-related neurodegeneration, but these findings are still correlative and do not prove causation. Indeed in the one model that did not observe C-terminal fragments of TDP-43, sub-lethal TDP-43 toxicity to motor neurons was clearly documented [42]. Therefore, further work is certainly needed to clarify how and why the fragments are generated, and whether they are a direct mediator or instead a byproduct of TDP-43 toxicity.

\section{Loss of Nuclear TDP-43 as a Mechanism of \\ Neurodegeneration}

In addition to the presence of TDP-43 inclusions, loss of nuclear TDP-43 staining is commonly observed in affected neurons in ALS and FTLD [9] (fig. 1a), leading to the suggestion that a secondary loss of TDP-43 function may be involved in neurodegeneration [13]. To understand the effects of loss of TDP-43, several groups have generated TDP-43 null alleles in mice [57-59]. In all cases, homozygous null mice showed early embryonic lethality due to defective outgrowth of the inner cell mass. Heterozygous mutant mice were normal and did not display pathologic changes in the brain or spinal cord, though 1 group reported subtle behavioral abnormalities in aged mice [59]. These studies indicate that TDP-43 is essential for embryonic development, and are consistent with a role for TDP-43 in fundamental aspects of RNA metabolism. Furthermore it is consistent with the observation that loss of TDP-43 is toxic even in cultured cells $[60,61]$, and may relate to why TDP-43 shows such marked toxicity when overexpressed during development.

Whether loss of TDP-43 in mature neurons causes neurodegeneration in ALS or FTLD remains to be answered. However a recent report showed that removal of TDP-43 globally from adult mice (using a floxed Tardbp allele crossed to Rosa26-ErCre mice, treated as adults with tamoxifen) led to rapid demise within $\sim 9$ days [62]. These mice had selective loss of body fat due to increased fatty acid oxidation, possibly from to misregulation of the putative TDP-43 target gene Tbcld1. Though the relevance of this finding to neurodegeneration in ALS and FTLD remains unclear, the finding is intriguing as alterations in fatty acid metabolism have previously been proposed to play a role in ALS pathogenesis [63].

Similar to observations in human ALS and FTLD brains and spinal cords, several of the transgenic rodent models showed loss of nuclear TDP-43 staining in selectively vulnerable neurons prior to overt degeneration [37, 38]. In some cases this corresponded to an increase of TDP-43 in the cytosol. These findings are consistent with 
the possibility that loss of nuclear TDP-43 plays a role in neurodegeneration, though the reason for TDP-43 translocation from the nucleus remains unclear. One must keep in mind that translocation of TDP-43 from the nucleus to the cytosol has also been observed in motor neurons after axotomy [64], and therefore further studies are needed to determine if this change in the subcellular distribution of TDP-43 is mediating disease or is simply a nonspecific response to injury.

\section{Altered or Gain of Nuclear TDP-43 Function as a}

Mechanism of Neurodegeneration from TDP-43

Mutations or Overexpression

While loss of nuclear TDP-43 function is frequently discussed as a potential basis of TDP-43-related neurodegeneration, another possibility is that ALS-associated TDP-43 mutations (or simply TDP-43 overexpression in the case of the transgenic mouse models) may alter protein binding partners or DNA/RNA targets thus leading to toxicity, either through changes in alternative splicing, transcriptional regulation, or other nuclear TDP-43 functions. In this respect, 1 report found that overexpression of wild-type TDP-43 in mice led to an increased number of Gemini bodies in the nucleus [42]. Gemini bodies are rich in SMN (survival motor neuron) protein, and are required for assembling snRNPs, critical components of the pre-mRNA splicing apparatus. Decreased levels of SMN protein lead to a childhood onset motor neuron disease called spinal muscular atrophy [65]. A previous study indicated that TDP-43 overexpression enhances exon 7 inclusion and stability of the SMN2 transcript in cultured cells [66], which could in part be responsible for the altered SMN distribution and increased numbers of Gemini bodies in these mice. Whether increased numbers of Gemini bodies somehow damage motor neurons remains to be determined, and this may be only 1 of many toxic effects which occur due to TDP43 overexpression in the nucleus.

\section{Selective Vulnerability and Altered Protein Homeostasis as Key Features in TDP-43 Transgenic Models}

The fact that overexpression of wild-type TDP- 43 can be toxic to immortalized tumor cell lines [33-35] raises concern that when TDP-43 is overexpressed in a rodent, fly or worm model, the toxicity observed may be unrelated to the mechanism of how TDP-43 mutations cause ALS in humans. However, the most promising finding in the rodent models reported thus far is that despite widespread transgenic expression of TDP-43 in neurons throughout the brain and in other tissues, TDP-43 toxicity shows a striking predilection for spinal motor neurons and cortical layer V neurons, across several different promoters $[37,38,43]$. This parallels the cell populations predominantly affected in human ALS and FTLD, and is perhaps the strongest argument that the toxicity observed in rodent models overexpressing TDP-43 is not nonspecific, but instead is due to alterations in key molecular pathways involved in human ALS and FTLD. This provides a remarkable opportunity to study the molecular basis of selective vulnerability of this set of neurons to TDP-43 toxicity.

Dysfunctional protein homeostasis with abnormal accumulations of ubiquitinated proteins is a unifying theme across most neurodegenerative diseases [67]. In both ALS and FTLD, ubiquitinated cytoplasmic inclusions are a prominent finding in the brain and spinal cord of patients $[68,69]$. In Prp-TDP43 ${ }^{\mathrm{A} 315 \mathrm{~T}}$ mice, cytoplasmic accumulation of ubiquitinated proteins occurred preferentially in layer $\mathrm{V}$ pyramidal neurons and spinal motor neurons prior to neuron loss [37], with similar findings seen in Thy1.2-TDP43 ${ }^{\mathrm{WT}}$ mice [38]. This indicates that altered protein homeostasis with accumulation of misfolded proteins preceded neurodegeneration. Transgenic expression of ALS mutant TDP43 $3^{\mathrm{M} 337 \mathrm{~V}}$ in rats also showed selective damage of spinal motor neurons at early stages with increased ubiquitin staining, though cytoplasmic inclusions were not seen [43]. Given that TDP-43 itself is not a major component of these inclusions, future studies are needed to determine whether TDP-43 directly or indirectly leads to altered protein homeostasis in selectively vulnerable cells.

\section{Comparison of TDP-43 and SOD1 Rodent Models of ALS}

Mutations in SOD1 are found in $\sim 20 \%$ of familial ALS cases, and transgenic rodents expressing mutant SOD1 are the gold standard for animal-based ALS research as they develop progressive motor neuron degeneration and premature death $[4,70]$. SOD1 is a ubiquitously expressed polypeptide whose best-understood function is the conversion of superoxide to water and hydrogen peroxide. In marked contrast to the embryonic lethality of TDP-43 null mice, SOD1 null mice are viable and do not develop motor neuron disease, supporting that loss of SOD1 function is not involved in ALS 
pathogenesis [71]. Most transgenic SOD1 animals have been engineered using the endogenous SOD1 promoter, which drives ubiquitous expression. Interestingly, mutant SOD1 overexpression must be achieved at very high levels (at least $20 \times$ over endogenous) to cause motor neuron disease within the mouse life span [72], in marked contrast to the severe neurodegeneration observed with lower level overexpression of TDP-43 (likely in the range of $\sim 3$-fold). Interestingly, mice overexpressing wild-type SOD1 also develop motor neuron disease, but with subclinical pathology and without premature death [73]. Though analogous to the toxicity observed with wildtype TDP-43, it is clear that the relative toxicity of mutant to wild-type protein is much greater for SOD1 than it is for TDP-43 (fig. 2).

The most widely studied SOD1 transgenic models express the G93A or G37R mutations, and show weakness starting in the hindlimbs and progressing to paralysis and premature death, with severity of phenotype increasing with increased copy number. Lower motor neurons appear most vulnerable to mutant SOD1 toxicity, with gait abnormalities and weight loss correlating with lower motor neuron loss, and relatively little cortical and corticospinal tract involvement reported [74]. By contrast, Prp-TDP43 ${ }^{\mathrm{A} 315 \mathrm{~T}}$ mice show cortical and descending corticospinal tract pathology before developing lower motor neuron degeneration correlating with the onset of gait abnormalities [37]. This suggests that although both SOD1 and TDP-43 cause toxicity predominantly to the motor system in mice, they appear to involve upper and lower motor neurons to different degrees.

Microglia are key mediators of neuroinflammation and along with macroglia become activated during times of stress or injury to the nervous system [75], and in ALS are present in vulnerable regions of motor neuron loss $[76,77]$. In SOD1 rodent models, proinflammatory mediators are expressed early in disease, supporting a possible role in disease initiation or progression [78]. Furthermore, extensive analysis using conditional removal of SOD1 in different cell types has shown that SOD1 toxicity is not cell autonomous to neurons, and that microglia and astrocytes play a key role in disease progression $[79,80]$. Similar to the SOD1 models, the reported TDP-43 transgenic rodent models show that neurodegeneration is accompanied by marked microglial and astrocytic activation, with striking selectivity for cortical layer V in some cases [37-39, 41]. It is important to point out that the promoters used to generate existing TDP-43 transgenic mice are not expressed in microglia. Furthermore while mPrp is expressed widely in both neurons and astrocytes, the Thy- 1.2 promoter is largely neuronal specific. Therefore, although more carefully targeted studies examining cell autonomy remain to be performed, preliminary evidence suggests that TDP-43 toxicity can autonomously be initiated by the neuron $[38,40]$.

As with the TDP-43 models, SOD1 mutant transgenic mice show ubiquitin positive intracellular inclusions in motor neurons suggesting altered protein homeostasis may play a common role in neurodegeneration in both models [74]. However, misfolded SOD1 appears to be a key component of ubiquitinated inclusions in these mice, in contrast to the conspicuous lack of TDP-43 in most ubiquitinated inclusions in TDP-43 transgenic mice discussed above. Therefore although altered protein degradation pathways is a common feature, the mechanism by which SOD1 and TDP-43 alters protein homeostasis may differ. Other features reported in SOD1 mutant mice including axonal transport defects and glutamate mediated excitotoxicity remain to be characterized in TDP-43 transgenic rodents [41].

\section{Drosophila and C. Elegans TDP-43 Models}

Invertebrate models offer powerful genetic tools, and now are frequently among the first animal models generated for newly identified neurodegenerative disease genes [81]. TDP-43 has functionally conserved homologues in both flies and worms [12]. Similar to mice, loss of TDP-43 function is deleterious, as deletion of the Drosophila homologue TBPH results in a semi-lethal [82-84] or lethal phenotype [85]. TBPH null flies that do survive show axonal loss and neuronal death [84], locomotive defects, reduced life span, and abnormal neuromuscular junctions [82], which can be partly rescued by expression of TDP43 in motor neurons [82].

Overexpression of human TDP-43 is also sufficient to cause neurodegeneration in Drosophila or C. elegans when driven selectively in neurons [35, 84, 86, 87]. Decreased locomotion and age-dependant axonal loss and neuronal death were observed when TDP-43 was expressed in mushroom bodies or motor neurons of flies [84]. The severity of the phenotype was dose-dependent, with higher expressing lines not surviving past the larval stage, and lower expressing lines showing movement defects, paralysis, and death [86]. When wild-type and M337V versions of TDP-43 were overexpressed in the fly eye, a modest degenerative phenotype was observed with wild-type TDP-43, but in the M337V disease mutant the 
phenotype was more severe [87]. This again suggests that though wild-type TDP-43 overexpression can itself be toxic, mutant forms of the protein may be more so. Of note: unlike the rodent models, TDP-43 overexpression in Drosophila and C. elegans has been performed only using neuronal specific promoters. Therefore, whether TDP-43 is selectively toxic to specific cell populations such as motor neurons has not been demonstrated in invertebrates as it has in rodent models.

While TDP-43 overexpression is clearly toxic in flies and worms, other features of TDP-43 pathology (ubiquitinated aggregates, TDP-43 fragmentation, cytoplasmic translocation and loss of nuclear TDP-43) have been less consistently reported. In flies overexpressing TDP-43, one study reported detergent insoluble full length TDP43 [84], while another found detergent soluble C-terminal fragments [87], and a third found neither of these despite clear TDP-43 toxicity [86].

As with rodent models, the exact site of TDP-43 toxicity (nucleus versus cytoplasm) remains unclear in fly and worm models. One study in flies reported that mislocalizing TDP-43 to the cytosol by mutating the nuclear localization signal (NLS) caused a degenerative phenotype similar to the wild-type protein, suggesting that the toxicity of TDP-43 occurs in the cytoplasm [87]. By contrast, the same NLS mutant expressed in worms was not toxic, leading to the suggestion that TDP-43 toxicity primarily occurs in the nucleus [35]. The origin of this discrepancy remains to be determined.

Despite apparent inconsistencies in certain aspects of the mechanism of TDP-43-related toxicity in lower organisms, it is clear that the identification of genetic modifiers remains the strength of the invertebrate models. This was nicely demonstrated by showing that ubiquilin (a known TDP-43 binding partner) [86] or ataxin-2 [88] can modify TDP-43 toxicity in invertebrate models, sup- porting that such screens will be useful for identifying proteins and pathways involved in TDP-43 mediated neurodegeneration.

\section{Conclusion}

The identification of mutations in TDP-43 in patients with familial ALS has represented a true breakthrough in ALS research, indicating that abnormalities in TDP-43 function can be a primary event in a cascade leading to neurodegeneration of a selective group of neurons. Furthermore, it appears that overexpression of TDP-43 in rodents can produce an ALS/FTLD like phenotype, suggesting that the molecular and cellular substrates of TDP43 toxicity and selective vulnerability are shared between rodents and humans. Though the initial crop of rodent and invertebrate models have shown promise, as expected many questions remain. These include to what degree the wild-type and disease mutant forms of TDP- 43 differ in their toxicity, what is the primary site of TDP-43 toxicity (nuclear, cytoplasm or both), and whether a loss or alteration in normal TDP-43 DNA/RNA binding protein function plays a role in disease. Though these questions are daunting, answering them may very well hold the key to developing effective therapies which are sorely needed for ALS and FTLD.

\section{Acknowledgements}

R.H.B is supported by National Institutes of Health (NIH) grants K08 NS055980 and R01 NS069669, the Muscular Dystrophy Association (135428), the Children's Discovery Institute, and holds a Career Award for Medical Scientists from the Burroughs Wellcome Fund. I.W. is supported by a Ruth Kirschstein National Research Service Award.

\section{References}

1 Bruijn LI, Miller TM, Cleveland DW: Unraveling the mechanisms involved in motor neuron degeneration in ALS. Annu Rev Neurosci 2004;27:723-749.

$\checkmark 2$ Siddique T, Lalani I: Genetic aspects of amyotrophic lateral sclerosis. Adv Neurol 2002; 88:21-32.

$\checkmark 3$ Rosen DR, Siddique T, Patterson D, Figlewicz DA, Sapp P, Hentati A, Donaldson D, Goto J, O'Regan JP, Deng HX, et al: Mutations in $\mathrm{Cu} / \mathrm{Zn}$ superoxide dismutase gene are associated with familial amyotrophic lateral sclerosis. Nature 1993;362:59-62.
4 Benatar M: Lost in translation: treatment trials in the SOD1 mouse and in human ALS. Neurobiol Dis 2007;26:1-13.

5 Murphy J, Henry R, Lomen-Hoerth C: Establishing subtypes of the continuum of frontal lobe impairment in amyotrophic lateral sclerosis. Arch Neurol 2007;64:330-334.

-6 Seeley WW: Selective functional, regional, and neuronal vulnerability in frontotemporal dementia. Curr Opin Neurol 2008;21: 701-707.
7 Geser F, Martinez-Lage M, Robinson J, Uryu K, Neumann M, Brandmeir NJ, Xie SX, Kwong LK, Elman L, McCluskey L, Clark CM, Malunda J, Miller BL, Zimmerman EA, Qian J, Van Deerlin V, Grossman M, Lee VM, Trojanowski JQ: Clinical and pathological continuum of multisystem TDP-43 proteinopathies. Arch Neurol 2009;66:180-189.

$>8$ Lomen-Hoerth C, Anderson T, Miller B: The overlap of amyotrophic lateral sclerosis and frontotemporal dementia. Neurology 2002; 59:1077-1079. 
9 Neumann M, Sampathu DM, Kwong LK, Truax AC, Micsenyi MC, Chou TT, Bruce J, Schuck T, Grossman M, Clark CM, McCluskey LF, Miller BL, Masliah E, Mackenzie IR, Feldman H, Feiden W, Kretzschmar HA, Trojanowski JQ, Lee VM: Ubiquitinated TDP-43 in frontotemporal lobar degeneration and amyotrophic lateral sclerosis. Science 2006;314:130-133.

10 Acharya KK, Govind CK, Shore AN, Stoler $\mathrm{MH}$, Reddi PP: cis-requirement for the maintenance of round spermatid-specific transcription. Dev Biol 2006;295:781-790.

-11 Buratti E, Baralle FE: Characterization and functional implications of the RNA binding properties of nuclear factor TDP-43, a novel splicing regulator of CFTR exon 9. J Biol Chem 2001;276:36337-36343.

- 12 Ayala YM, Pantano S, D’Ambrogio A, Buratti E, Brindisi A, Marchetti C, Romano M, Baralle FE: Human, Drosophila, and C. elegans TDP43: nucleic acid binding properties and splicing regulatory function. J Mol Biol 2005;348:575-588.

-13 Buratti E, Baralle FE: The molecular links between TDP-43 dysfunction and neurodegeneration. Adv Genet 2009;66:1-34.

-14 Gitcho MA, Baloh RH, Chakraverty S, Mayo K, Norton JB, Levitch D, Hatanpaa KJ, White CL 3rd, Bigio EH, Caselli R, Baker M, AlLozi MT, Morris JC, Pestronk A, Rademakers R, Goate AM, Cairns NJ: TDP-43 A315T mutation in familial motor neuron disease. Ann Neurol 2008;63:535-538.

15 Kabashi E, Valdmanis PN, Dion P, Spiegelman D, McConkey BJ, Vande Velde C, Bouchard JP, Lacomblez L, Pochigaeva K, Salachas F, Pradat PF, Camu W, Meininger V, Dupre N, Rouleau GA: TARDBP mutations in individuals with sporadic and familial amyotrophic lateral sclerosis. Nat Genet 2008;40:572-574.

-16 Sreedharan J, Blair IP, Tripathi VB, Hu X, Vance C, Rogelj B, Ackerley S, Durnall JC, Williams KL, Buratti E, Baralle F, de Belleroche J, Mitchell JD, Leigh PN, Al-Chalabi A, Miller CC, Nicholson G, Shaw CE: TDP43 mutations in familial and sporadic amyotrophic lateral sclerosis. Science 2008;319: 1668-1672.

17 Yokoseki A, Shiga A, Tan CF, Tagawa A, Kaneko H, Koyama A, Eguchi H, Tsujino A, Ikeuchi T, Kakita A, Okamoto K, Nishizawa M, Takahashi H, Onodera O: TDP-43 mutation in familial amyotrophic lateral sclerosis. Ann Neurol 2008;63:538-542.

18 Van Deerlin VM, Leverenz JB, Bekris LM, Bird TD, Yuan W, Elman LB, Clay D, Wood EM, Chen-Plotkin AS, Martinez-Lage M, Steinbart E, McCluskey L, Grossman M, Neumann M, Wu IL, Yang WS, Kalb R, Galasko DR, Montine TJ, Trojanowski JQ, Lee VM, Schellenberg GD, Yu CE: TARDBP mutations in amyotrophic lateral sclerosis with TDP-43 neuropathology: a genetic and histopathological analysis. Lancet Neurol 2008;7:409-416.
Benajiba L, Le Ber I, Camuzat A, Lacoste M, Thomas-Anterion C, Couratier P, Legallic S, Salachas F, Hannequin D, Decousus M, Lacomblez L, Guedj E, Golfier V, Camu W, Dubois B, Campion D, Meininger V, Brice A: TARDBP mutations in motoneuron disease with frontotemporal lobar degeneration. Ann Neurol 2009;65:470-473.

$\checkmark 20$ Gitcho MA, Bigio EH, Mishra M, Johnson N, Weintraub S, Mesulam M, Rademakers R, Chakraverty S, Cruchaga C, Morris JC, Goate AM, Cairns NJ: TARDBP 3'-UTR variant in autopsy-confirmed frontotemporal lobar degeneration with TDP-43 proteinopathy. Acta Neuropathol 2009;118: 633-645.

21 Kovacs GG, Murrell JR, Horvath S, Haraszti L, Majtenyi K, Molnar MJ, Budka H, Ghetti $B$, Spina S: TARDBP variation associated with frontotemporal dementia, supranuclear gaze palsy, and chorea. Mov Disord 2009;24: 1843-1847.

22 Borroni B, Bonvicini C, Alberici A, Buratti E, Agosti C, Archetti S, Papetti A, Stuani C, Di Luca M, Gennarelli M, Padovani A: Mutation within TARDBP leads to frontotemporal dementia without motor neuron disease. Hum Mutat 2009;30:E974-E983.

23 Fuentealba RA, Udan M, Bell S, Wegorzewska I, Shao J, Diamond MI, Weihl CC, Baloh $\mathrm{RH}$ : Interaction with polyglutamine aggregates reveals a $\mathrm{Q} / \mathrm{N}$ rich domain in TDP-43. J Biol Chem 2010;285:26304-26314.

-24 Kwiatkowski TJ Jr, Bosco DA, Leclerc AL, Tamrazian E, Vanderburg CR, Russ C, Davis A, Gilchrist J, Kasarskis EJ, Munsat T, Valdmanis P, Rouleau GA, Hosler BA, Cortelli P, de Jong PJ, Yoshinaga Y, Haines JL, PericakVance MA, Yan J, Ticozzi N, Siddique T, McKenna-Yasek D, Sapp PC, Horvitz HR, Landers JE, Brown RH Jr: Mutations in the FUS/TLS gene on chromosome 16 cause familial amyotrophic lateral sclerosis. Science 2009;323:1205-1208.

25 Vance C, Rogelj B, Hortobagyi T, De Vos KJ, Nishimura AL, Sreedharan J, Hu X, Smith B, Ruddy D, Wright P, Ganesalingam J, Williams KL, Tripathi V, Al-Saraj S, Al-Chalabi A, Leigh PN, Blair IP, Nicholson G, de Belleroche J, Gallo JM, Miller CC, Shaw CE: Mutations in FUS, an RNA processing protein, cause familial amyotrophic lateral sclerosis type 6. Science 2009;323:1208-1211.

26 Kim SH, Shanware N, Bowler MJ, Tibbetts RS: ALS-associated proteins TDP-43 and FUS/TLS function in a common biochemical complex to coregulate HDAC6 mRNA. J Biol Chem 2010;285:34097-34105.

27 Ling SC, Albuquerque CP, Han JS, LagierTourenne C, Tokunaga S, Zhou H, Cleveland DW: ALS-associated mutations in TDP-43 increase its stability and promote TDP-43 complexes with FUS/TLS. Proc Natl Acad Sci USA 2010;107:13318-13323.
8 Deng HX, Zhai H, Bigio EH, Yan J, Fecto F, Ajroud K, Mishra M, Ajroud-Driss S, Heller S, Sufit R, Siddique N, Mugnaini E, Siddique T: FUS-immunoreactive inclusions are a common feature in sporadic and non-SOD1 familial amyotrophic lateral sclerosis. Ann Neurol 2010;67:739-748.

-29 Higashi S, Iseki E, Yamamoto R, Minegishi M, Hino H, Fujisawa K, Togo T, Katsuse O, Uchikado H, Furukawa Y, Kosaka K, Arai H: Concurrence of TDP-43, tau and alphasynuclein pathology in brains of Alzheimer's disease and dementia with Lewy bodies. Brain Res 2007;1184:284-294.

30 Josephs KA, Whitwell JL, Knopman DS, Hu WT, Stroh DA, Baker M, Rademakers R, Boeve BF, Parisi JE, Smith GE, Ivnik RJ, Petersen RC, Jack CR Jr, Dickson DW: Abnormal TDP-43 immunoreactivity in AD modifies clinicopathologic and radiologic phenotype. Neurology 2008;70:1850-1857.

-31 Schwab C, Arai T, Hasegawa M, Yu S, McGeer PL: Colocalization of transactivationresponsive DNA-binding protein 43 and huntingtin in inclusions of Huntington disease. J Neuropathol Exp Neurol 2008;67: 1159-1165.

32 Weihl CC, Temiz P, Miller SE, Watts G, Smith C, Forman M, Hanson PI, Kimonis V, Pestronk A: TDP-43 accumulation in inclusion body myopathy muscle suggests a common pathogenic mechanism with frontotemporal dementia. J Neurol Neurosurg Psychiatry 2008;79:1186-1189.

-33 Ayala YM, Misteli T, Baralle FE: TDP-43 regulates retinoblastoma protein phosphorylation through the repression of cyclin-dependent kinase 6 expression. Proc Natl Acad Sci USA 2008; 105:3785-3789.

- 34 Zhang YJ, Xu YF, Cook C, Gendron TF, Roettges P, Link CD, Lin WL, Tong J, Castanedes-Casey M, Ash P, Gass J, Rangachari V, Buratti E, Baralle F, Golde TE, Dickson DW, Petrucelli L: Aberrant cleavage of TDP43 enhances aggregation and cellular toxicity. Proc Natl Acad Sci USA 2009; 106:7607-7612.

- 35 Ash PE, Zhang YJ, Roberts CM, Saldi T, Hutter H, Buratti E, Petrucelli L, Link CD: Neurotoxic effects of TDP-43 overexpression in C. elegans. Hum Mol Genet 2010;19:32063218.

36 Gurney ME: Transgenic-mouse model of amyotrophic lateral sclerosis. N Engl J Med 1994;331:1721-1722.

37 Wegorzewska I, Bell S, Cairns NJ, Miller TM, Baloh RH: TDP-43 mutant transgenic mice develop features of ALS and frontotemporal lobar degeneration. Proc Natl Acad Sci USA 2009;106:18809-18814.

38 Wils H, Kleinberger G, Janssens J, Pereson S, Joris G, Cuijt I, Smits V, Groote CC, Van Broeckhoven C, Kumar-Singh S: TDP-43 transgenic mice develop spastic paralysis and neuronal inclusions characteristic of ALS and frontotemporal lobar degeneration. Proc Natl Acad Sci USA 2010;107:38583863. 
-39 Stallings NR, Puttaparthi K, Luther CM, 50 Chen-Plotkin AS, Lee VM, Trojanowski JQ: Burns DK, Elliott JL: Progressive motor weakness in transgenic mice expressing human TDP-43. Neurobiol Dis 2010;40:404414.

-40 Tsai KJ, Yang CH, Fang YH, Cho KH, Chien WL, Wang WT, Wu TW, Lin CP, Fu WM, Shen CK: Elevated expression of TDP-43 in the forebrain of mice is sufficient to cause neurological and pathological phenotypes mimicking FTLD-U. J Exp Med 2010;207: 1661-1673.

$41 \mathrm{Xu}$ YF, Gendron TF, Zhang YJ, Lin WL, D'Alton S, Sheng H, Casey MC, Tong J, Knight J, Yu X, Rademakers R, Boylan K, Hutton M, McGowan E, Dickson DW, Lewis J, Petrucelli L: Wild-type human TDP-43 expression causes TDP-43 phosphorylation, mitochondrial aggregation, motor deficits, and early mortality in transgenic mice. J Neurosci 2010;30:10851-10859.

42 Shan X, Chiang PM, Price DL, Wong PC: Altered distributions of Gemini of coiled bodies and mitochondria in motor neurons of TDP-43 transgenic mice. Proc Natl Acad Sci USA 2010;107:16325-16330.

-43 Zhou H, Huang C, Chen H, Wang D, Landel CP, Xia PY, Bowser R, Liu YJ, Xia XG: A transgenic rat model of neurodegeneration caused by mutation in the TDP gene. PLoS Genet 2010;6:e1000887.

-44 Borchelt DR, Ratovitski T, van Lare J, Lee MK, Gonzales V, Jenkins NA, Copeland NG, Price DL, Sisodia SS: Accelerated amyloid deposition in the brains of transgenic mice coexpressing mutant presenilin 1 and amyloid precursor proteins. Neuron 1997;19: 939-945.

-45 Wang J, Xu G, Slunt HH, Gonzales V, Coonfield M, Fromholt D, Copeland NG, Jenkins NA, Borchelt DR: Coincident thresholds of mutant protein for paralytic disease and protein aggregation caused by restrictively expressed superoxide dismutase cDNA. Neurobiol Dis 2005;20:943-952.

-46 Vidal M, Morris R, Grosveld F, Spanopoulou E: Tissue-specific control elements of the Thy-1 gene. Embo J 1990;9:833-840.

$\checkmark 47$ Caroni P: Overexpression of growth-associated proteins in the neurons of adult transgenic mice. J Neurosci Methods 1997;71:3-9.

-48 Feng G, Mellor RH, Bernstein M, KellerPeck C, Nguyen QT, Wallace M, Nerbonne JM, Lichtman JW, Sanes JR: Imaging neuronal subsets in transgenic mice expressing multiple spectral variants of GFP. Neuron 2000;28:41-51.

-49 Mayford M, Bach ME, Huang YY, Wang L, Hawkins RD, Kandel ER: Control of memory formation through regulated expression of a CaMKII transgene. Science 1996;274: 1678-1683.
TAR DNA-binding protein 43 in neurode211-220.

-51 Lagier-Tourenne C, Polymenidou M, Cleveland DW: TDP-43 and FUS/TLS: emerging roles in RNA processing and neurodegeneration. Hum Mol Genet 2010;19:R46-R64.

52 Davidson Y, Kelley T, Mackenzie IR, Pickering-Brown S, Du Plessis D, Neary D, Snowden JS, Mann DM: Ubiquitinated pathological lesions in frontotemporal lobar degeneration contain the TAR DNA-binding protein, TDP-43. Acta Neuropathol 2007;113:521533.

53 Arai T, Hasegawa M, Akiyama H, Ikeda K, Nonaka T, Mori H, Mann D, Tsuchiya K, Yoshida M, Hashizume Y, Oda T: TDP-43 is a component of ubiquitin-positive tau-negative inclusions in frontotemporal lobar degeneration and amyotrophic lateral sclerosis. Biochem Biophys Res Commun 2006;351: 602-611.

54 Magrane J, Manfredi G: Mitochondrial function, morphology, and axonal transport in amyotrophic lateral sclerosis. Antioxid Redox Signal 2009;11:1615-1626.

55 Johnson BS, Snead D, Lee JJ, McCaffery JM, Shorter J, Gitler AD: TDP-43 is intrinsically aggregation-prone, and amyotrophic lateral sclerosis-linked mutations accelerate aggregation and increase toxicity. J Biol Chem 2009;284:20329-20339.

56 Igaz LM, Kwong LK, Chen-Plotkin A, Winton MJ, Unger TL, Xu Y, Neumann M, Trojanowski JQ, Lee VM: Expression OfTDP-43 C-terminal fragments in vitro recapitulates pathological features of TDP-43 proteinopathies. J Biol Chem 2009;284:8516-8524.

$57 \mathrm{Wu}$ LS, Cheng WC, Hou SC, Yan YT, Jiang ST, Shen CK: TDP-43, a neuro-pathosignature factor, is essential for early mouse embryogenesis. Genesis 2010;48:56-62.

58 Sephton CF, Good SK, Atkin S, Dewey CM, Mayer P 3rd, Herz J, Yu G: TDP-43 is a developmentally regulated protein essential for early embryonic development. J Biol Chem 2010;285:6826-6834.

59 Kraemer BC, Schuck T, Wheeler JM, Robinson LC, Trojanowski JQ, Lee VM, Schellenberg GD: Loss of murine TDP-43 disrupts motor function and plays an essential role in embryogenesis. Acta Neuropathol 2010;119: 409-419.

60 Ayala YM, Zago P, D’Ambrogio A, Xu YF, Petrucelli L, Buratti E, Baralle FE: Structural determinants of the cellular localization and shuttling of TDP-43. J Cell Sci 2008;121: 3778-3785.

61 Iguchi Y, Katsuno M, Niwa J, Yamada S, Sone J, Waza M, Adachi H, Tanaka F, Nagata K, Arimura N, Watanabe T, Kaibuchi K, Sobue G: TDP-43 depletion induces neuronal cell damage through dysregulation of Rho family GTPases. J Biol Chem 2009;284:2205922066. generative disease. Nat Rev Neurol 2010;6;
62 Chiang PM, Ling J, Jeong YH, Price DL, Aja SM, Wong PC: Deletion of TDP-43 downregulates Tbcld1, a gene linked to obesity, and alters body fat metabolism. Proc Natl Acad Sci USA 2010;107:16320-16324.

63 Dupuis L, Oudart H, Rene F, Gonzalez de Aguilar JL, Loeffler JP: Evidence for defective energy homeostasis in amyotrophic lateral sclerosis: benefit of a high-energy diet in a transgenic mouse model. Proc Natl Acad Sci USA 2004;101:11159-11164.

64 Moisse K, Volkening K, Leystra-Lantz C, Welch I, Hill T, Strong MJ: Divergent patterns of cytosolic TDP-43 and neuronal progranulin expression following axotomy: implications for TDP-43 in the physiological response to neuronal injury. Brain Res 2009; 1249:202-211.

65 Lorson CL, Rindt H, Shababi M: Spinal muscular atrophy: mechanisms and therapeutic strategies. Hum Mol Genet 2010;19:R111R118.

66 Bose JK, Wang IF, Hung L, Tarn WY, Shen CK: TDP-43 overexpression enhances exon 7 inclusion during the survival of motor neuron pre-mRNA splicing. J Biol Chem 2008; 283:28852-28859.

67 Winklhofer KF, Tatzelt J, Haass C: The two faces of protein misfolding: gain- and lossof-function in neurodegenerative diseases. Embo J 2008;27:336-349.

68 Cairns NJ, Neumann M, Bigio EH, Holm IE, Troost D, Hatanpaa KJ, Foong C, White CL, 3rd, Schneider JA, Kretzschmar HA, Carter D, Taylor-Reinwald L, Paulsmeyer K, Strider J, Gitcho M, Goate AM, Morris JC, Mishra M, Kwong LK, Stieber A, Xu Y, Forman MS, Trojanowski JQ, Lee VM, Mackenzie IR: TDP-43 in familial and sporadic frontotemporal lobar degeneration with ubiquitin inclusions. Am J Pathol 2007;171:227-240.

69 Leigh PN, Whitwell H, Garofalo O, Buller J, Swash M, Martin JE, Gallo JM, Weller RO, Anderton BH: Ubiquitin-immunoreactive intraneuronal inclusions in amyotrophic lateral sclerosis. Morphology, distribution, and specificity. Brain 1991;114:775-788.

70 Rothstein JD: Of mice and men: reconciling preclinical ALS mouse studies and human clinical trials. Ann Neurol 2003;53:423-426.

-71 Reaume AG, Elliott JL, Hoffman EK, Kowall NW, Ferrante RJ, Siwek DF, Wilcox HM, Flood DG, Beal MF, Brown RH Jr, Scott RW, Snider WD: Motor neurons in Cu/Zn superoxide dismutase-deficient mice develop normally but exhibit enhanced cell death after axonal injury. Nat Genet 1996;13:43-47.

72 Jonsson PA, Graffmo KS, Andersen PM, Brannstrom T, Lindberg $M$, Oliveberg $M$, Marklund SL: Disulphide-reduced superoxide dismutase-1 in CNS of transgenic amyotrophic lateral sclerosis models. Brain 2006; 129:451-464. 
73 Jaarsma D: Swelling and vacuolisation of mitochondria in transgenic SOD1-ALS mice: a consequence of supranormal SOD1 expression? Mitochondrion 2006;6:48-49; author reply $50-51$.

74 Turner BJ, Talbot K: Transgenics, toxicity and therapeutics in rodent models of mutant SOD1-mediated familial ALS. Prog Neurobiol 2008;85:94-134.

75 Kreutzberg GW: Microglia: a sensor for pathological events in the CNS. Trends Neurosci 1996;19:312-318.

-76 Kawamata T, Akiyama H, Yamada T, McGeer PL: Immunologic reactions in amyotrophic lateral sclerosis brain and spinal cord tissue. Am J Pathol 1992;140:691-707.

-77 Ince PG, Shaw PJ, Slade JY, Jones C, Hudgson P: Familial amyotrophic lateral sclerosis with a mutation in exon 4 of the $\mathrm{Cu} / \mathrm{Zn}$ superoxide dismutase gene: pathological and immunocytochemical changes. Acta Neuropathol 1996;92:395-403.

78 Alexianu ME, Kozovska M, Appel SH: Immune reactivity in a mouse model of familial ALS correlates with disease progression. Neurology 2001;57:1282-1289.

79 Boillee S, Yamanaka K, Lobsiger CS, Copeland NG, Jenkins NA, Kassiotis G, Kollias G, Cleveland DW: Onset and progression in inherited ALS determined by motor neurons and microglia. Science 2006;312:1389-1392.
80 Lobsiger CS, Boillee S, McAlonis-Downes M, Khan AM, Feltri ML, Yamanaka K, Cleveland DW: Schwann cells expressing dismutase active mutant SOD1 unexpectedly slow disease progression in ALS mice. Proc Natl Acad Sci USA 2009;106:44654470.

81 Bilen J, Bonini NM: Drosophila as a model for human neurodegenerative disease. Annu Rev Genet 2005;39:153-171.

82 Feiguin F, Godena VK, Romano G, D’Ambrogio A, Klima R, Baralle FE: Depletion of TDP-43 affects Drosophila motoneurons terminal synapsis and locomotive behavior. FEBS Lett 2009;583:1586-1592.

$83 \mathrm{Lu}$ Y, Ferris J, Gao FB: Frontotemporal dementia and amyotrophic lateral sclerosis-associated disease protein TDP-43 promotes dendritic branching. Mol Brain 2009;2:30.

84 Li Y, Ray P, Rao EJ, Shi C, Guo W, Chen X, Woodruff EA 3rd, Fushimi K, Wu JY: A Drosophila model for TDP-43 proteinopathy. Proc Natl Acad Sci USA 2010;107:3169-3174.
85 Fiesel FC, Voigt A, Weber SS, Van den Haute C, Waldenmaier A, Gorner K, Walter M, Anderson ML, Kern JV, Rasse TM, Schmidt T, Springer W, Kirchner R, Bonin M, Neumann M, Baekelandt V, Alunni-Fabbroni M, Schulz JB, Kahle PJ: Knockdown of transactive response DNA-binding protein (TDP43) downregulates histone deacetylase 6 . Embo J 2010;29:209-221.

86 Hanson KA, Kim SH, Wassarman DA, Tibbetts RS: Ubiquilin modifies TDP-43 toxicity in a Drosophila model of amyotrophic lateral sclerosis (ALS). J Biol Chem 2010;285: 11068-11072.

87 Ritson GP, Custer SK, Freibaum BD, Guinto JB, Geffel D, Moore J, Tang W, Winton MJ, Neumann M, Trojanowski JQ, Lee VM, Forman MS, Taylor JP: TDP-43 mediates degeneration in a novel Drosophila model of disease caused by mutations in VCP/p97. J Neurosci 2010;30:7729-7739.

88 Elden AC, Kim HJ, Hart MP, Chen-Plotkin AS, Johnson BS, Fang X, Armakola M, Geser F, Greene R, Lu MM, Padmanabhan A, ClayFalcone D, McCluskey L, Elman L, Juhr D, Gruber PJ, Rub U, Auburger G, Trojanowski JQ, Lee VM, Van Deerlin VM, Bonini NM, Gitler AD: Ataxin-2 intermediate-length polyglutamine expansions are associated with increased risk for ALS. Nature 2010; 466:1069-1075. 